\title{
TURNOS DE COLETA E PERÍODOS DE TRANSFERÊNCIA DE OVOS DE MATRIZES SEMIPESADAS SOBRE PROCESSOS DE INCUBAÇÃO ARTIFICIAL
}

\author{
(Collection rounds and transfer periods of eggs from semi-heavy breeders on \\ artificial incubation procedures)
}

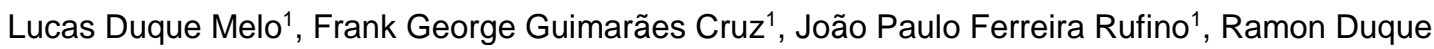
Melo $^{1}$, Julmar da Costa Feijó ${ }^{1}$, Ana Paula Guimarães Cruz Costa ${ }^{1}$

\begin{abstract}
${ }^{1}$ Faculdade de Ciências Agrárias, Universidade Federal do Amazonas, Amazonas, Brasil. "Corresponding author: frankgcruz@gmail.com
\end{abstract}

RESUMO: O objetivo deste estudo foi avaliar o efeito de diferentes turnos de coleta e diferentes períodos de transferência dos ovos de matrizes semipesadas sobre a relação pinto/ovo, rendimentos de incubação, mortalidade embrionária, análise térmica, análise do trato gastrointestinal e órgãos anexos, e desempenho dos pintos. $O$ delineamento experimental foi inteiramente casualizado em esquema fatorial $(3 \times 2)$ constituído de dois fatores: turnos de coleta (matutino, vespertino e noturno) e diferentes períodos de transferência dos ovos (16 e 19 dias), com 35 ovos por tratamento, sendo cada ovo considerado uma repetição. Os dados coletados foram submetidos à análise de variância e as médias estimadas avaliadas pelo teste de Tukey à $5 \%$ de significância. Foram observadas diferenças significativas $(p<0,05)$ para peso do ovo e peso do pinto entre turnos de coleta; na perda de peso do ovo entre períodos de transferência e nos rendimentos de incubação, na mortalidade tardia e temperatura da cloaca para ambos os fatores. Concluiu-se que turnos de coleta e períodos de transferência dos ovos podem influenciar diretamente os processos de incubação de ovos de matrizes semipesadas, com os turnos de coleta matutino e vespertino apresentando melhores resultados na relação pinto/ovo, rendimentos de incubação e mortalidade embrionária, com ovos e pintos menores. Ovos transferidos com 16 dias apresentaram melhores resultados de perda de peso do ovo, peso do pinto e rendimentos de incubação

Palavras-chave: conforto térmico, desempenho, incubação, mortalidade embrionária, pintos.

ABSTRACT: This study aimed to evaluate the effect of collection rounds and transfer periods of eggs from semi-heavy breeders on the chick/egg relationship, incubation yields, embryo mortality, thermodynamic analysis, gastrointestinal development and performance. The experimental method was completely randomized in factorial with two factors: collection rounds (morning - 8:00 at 12:00 hours, afternoon - 12:01 to 18:00 hours, and night - 18:01 to 7:59 hours) and different transfer periods of eggs (16 and 19 days), with 35 eggs per treatment, being the egg considered a replicate. Data collected were subjected to Tukey test at $5 \%$ of significance. Differences $(p<0.05)$ were observed to chick/egg weight among collection rounds; egg weight loss among transfer periods; and incubation yields, later mortality and cloaca temperature for both factors. It was concluded that collection rounds and transfer periods of eggs had directly influence on incubation processes. The morning and afternoon collection rounds showed better results for chick/egg relation, incubation yields and embryo mortality, with lowers eggs and 
chicks. Eggs transferred with 16 days showed better results of egg weight loss, chick weight and incubation yields.

Keywords: chicks, embryo mortality, incubation, performance, thermal comfort

\section{INTRODUÇÃO}

No processo de desenvolvimento embrionário, o ovário de uma ave em condições normais apresenta a chamada "hierarquia folicular", caracterizada por vários estágios de desenvolvimento que envolvem cerca de 10 a 12 folículos, liberados consecutivamente. As sequências são separadas por um período de pausa, que dura aproximadamente 40 horas. Desta forma, o ciclo de postura ocorre em dias sucessivos, seguidos de uma interrupção (pausa de postura) e um recomeço (NORTH, 1984; BARBOSA \& BAIÃO, 2011).

A partir deste contexto, o primeiro ovo de cada sequência é usualmente posto mais cedo, e os subsequentes são postos um pouco mais tarde nos dias seguintes. Portanto, grandes proporções dos ovos coletados no período da manhã são da primeira sequência ( $\mathrm{CHOl}$ et al.,1981). Desta forma, verifica-se uma importância do horário de ovoposição das aves e a programação do horário de coleta destes ovos.

$\mathrm{Na}$ produção industrial de ovos para incubação, buscam-se práticas para concentrar a postura nos ninhos, evitar a postura na cama e, consequentemente, a presença de ovos sujos. Tanto o manejo dos ninhos na pré-postura como a utilização de um número adequado de coletas diárias, contribuem na obtenção de ovos limpos e com menor grau de contaminação (BARBOSA et al., 2011).

$\mathrm{E}$ associadas a estas práticas, 0 incubatório apresenta-se como um ambiente estratégico da produção avícola e está fortemente vinculado à granja de matrizes. A principal meta do incubatório é transformar biologicamente ovos férteis em pintos de um dia no volume, prazo e qualidade desejados, minimizando a incidência de anormalidades e contaminação, de forma a atender às necessidades $e$ expectativas da produção avícola, ao menor custo (BRIAN, 2000).

$A$ viabilidade do embrião também pode ser comprometida durante a incubação decorrente dos parâmetros usados na mesma, incluindo as diferenças destes índices (principalmente temperatura, mas também de umidade e ventilação) existentes dentro das máquinas de incubação e posteriormente nas de nascimento (GIGLI et al, 2009).

O rendimento da incubação está estreitamente relacionado com a mortalidade embrionária, à qual sofre influência da gravidade específica e da capacidade do ovo em perder umidade. O acompanhamento dos resultados de incubação, para conhecimento sistemático dos índices de nascimento através da eclosão e da eclodibilidade, são fundamentais para avaliação dos possíveis fatores que limitam a produtividade do incubatório (TONA et al., 2003; BARBOSA et al., 2011).

Diante do exposto, realizou-se este trabalho com o objetivo de avaliar o efeito de diferentes turnos de coleta e diferentes períodos de transferência de ovos de matrizes semipesadas sobre a relação pinto sobre ovo, os rendimentos de incubação, mortalidade embrionária, análise térmica, análise do trato gastrointestinal e órgãos anexos, e desempenho dos pintos.

\section{MATERIAL E MÉTODOS}



processos de incubação artificial

O experimento foi realizado na Central de Incubação do Setor de Avicultura da Faculdade de Ciências Agrárias (FCA) da Universidade Federal do Amazonas (UFAM), localizado no Setor Sul do Campus Universitário, Manaus, Amazonas, Brasil.

Este trabalho foi aprovado junto ao Comitê de Ética no Uso de Animais (CEUA) da Universidade Federal do Amazonas sob o protocolo n. 010/2015.

Foram utilizadas 63 matrizes da linhagem Rhode Island Red com ração (distribuída pela parte da manhã) e água ad libitum. Os ovos foram coletados durante sete dias consecutivos sendo classificados conforme os turnos de coleta pré-determinados.

O delineamento experimental foi inteiramente casualizado em esquema fatorial $(3 \times 2)$ constituído pelos fatores: turnos de coleta (matutino - 8:00 às 12:00hs, vespertino - 12:01 às $18: 00 \mathrm{hs}$ e noturno 18:01 às 7:59hs) e diferentes períodos de transferência dos ovos (aos 16 e 19 dias), com 35 ovos por tratamento, sendo cada ovo considerado uma repetição.

Os ovos foram coletados e fumigados no galpão durante os dias de coleta, registrando-se cada ocorrência e classificando-se com base nos turnos de coleta, sendo armazenados em sala com temperatura de $18^{\circ} \mathrm{C}$ e umidade à $74 \%$ até o momento da incubação.

Antes da entrada dos ovos na incubadora, todos os ovos foram pesados e dispostos em badejas identificadas conforme o turno de coleta, sendo metade destes ovos reservada para ser transferida com 16 dias e outra metade com 19 dias. Foi utilizada máquina de incubação modelo PETERSIME 168 regulada para manter constante a temperatura do bulbo seco em $37,6 \stackrel{\circ}{\circ}$ e umidade relativa de $66 \%$.

Com 16 e 19 dias de incubação, dias pré-determinados para transferência, os ovos foram pesados para determinação da perda de peso do ovo e foi realizada ovoscopia para identificação dos ovos inférteis ou embriões mortos, além da determinação da taxa de fertilidade. Em seguida, os ovos foram transferidos para nascedouro modelo PETERSIME 168 com temperatura do bulbo seco em $36,6{ }^{\circ} \mathrm{C}$ e umidade relativa de $76 \%$.

A retirada dos pintos do nascedouro ocorreu com $504 \pm 2$ horas (21 dias), sendo registrado os pintos nascidos e os ovos não eclodidos de cada tratamento. A taxa de eclosão foi determinada através da relação do número de pintos nascidos e o número total de ovos, enquanto a taxa de eclodibilidade foi obtida através da relação entre 0 número de pintos nascidos e o número de ovos férteis.

Os ovos separados na ovoscopia e os que não eclodiram até 21 dias foram analisados para determinação da mortalidade embrionária, sendo avaliadas como precoce (1 a 7 dias), intermediária (8 a 14 dias), tardia (15 a 21 dias).

Os pintos nascidos foram separados ao nascimento e pesados a fim de calcular a correlação ovo-pinto. Após a pesagem, foram selecionados cinco pintos aptos de cada tratamento para mensuração da temperatura média superficial $\left(\mathrm{TMS}=3,47+0,11^{*}\right.$ Tasa + $0,1^{\star}$ Tcabeça + $0,15^{\star}$ Tperna + $0,56^{\star}$ Tdorso) e temperatura da cloaca, utilizando termômetro infravermelho CASON® CA380.

Em seguida, estes pintos foram abatidos por deslocamento cervical para mensuração do trato gastrointestinal e órgãos anexos: comprimento do sistema digestório $(\mathrm{cm})$, peso do coração $(\mathrm{g})$, peso dos estômagos (pró-ventrículo + moela) (g), peso do fígado (g) e peso do saco vitelino $(\mathrm{g})$.

Foram selecionados outros 10 pintos de cada tratamento para realização de análise de desempenho da progênie. Os pintos selecionados 
foram pesados e transferidos para gaiolas com aquecimento automático tipo criadeira, sendo separados por tratamento e alojados em compartimentos (5 pintos cada). Estes permaneceram nas gaiolas durante sete dias e tiveram diariamente avaliados seu desempenho avaliado: consumo de ração (g/ave), ganho de peso (g/ave) e conversão alimentar $(\mathrm{g} / \mathrm{g})$.

Os pintos foram alimentados com ração pré-inicial (tabela 1) conforme os níveis de garantia propostos pelas Tabelas Brasileiras para Aves e Suínos (ROSTAGNO et al., 2011).

Tabela 1. Ração pré-inicial fornecida aos pintos durante o período de desempenho.

\begin{tabular}{|c|c|}
\hline Ingredientes & $\begin{array}{l}\text { Quantidade } \\
\text { (Kg) }\end{array}$ \\
\hline Milho $(7,87 \%)$ & 66,930 \\
\hline F. de Soja (46\%) & 27,970 \\
\hline Calcário calcítico & 1,964 \\
\hline Fosfato bicálcico & 2,153 \\
\hline Sal comum & 0,350 \\
\hline DL-Metionina 99\% & 0,133 \\
\hline Supl. Vit./Mineral & 0,500 \\
\hline Total & 100,000 \\
\hline \multicolumn{2}{|l|}{ Níveis nutricionais } \\
\hline $\begin{array}{l}\text { Energia Metabolizável } \\
(\mathrm{kcal} / \mathrm{kg})\end{array}$ & $2.900,001$ \\
\hline Proteína Bruta (\%) & 18,000 \\
\hline Cálcio (\%) & 1,355 \\
\hline Metionina + Cistina (\%) & 0,710 \\
\hline Metionina Total (\%) & 0,406 \\
\hline Fósforo Disponível (\%) & 0,500 \\
\hline Sódio (\%) & 0,157 \\
\hline \multicolumn{2}{|c|}{$\begin{array}{l}\text { 'Suplemento Vit./mineral - inicial - contém em } 1 \\
\mathrm{~kg}=\text { Ácido fólico } 800 \mathrm{mg} \text {, Ácido Pantatênico } \\
12.500 \mathrm{mg} \text {, Antioxidante 0,5 g, Biotina } 40 \mathrm{mg} \text {, } \\
\text { Niacina } 33.600 \mathrm{mg} \text {, Selênio } 300 \mathrm{mg} \text {, Vit. A } \\
6.700 .000 \mathrm{Ul} \text {, Vit. B1 } 1.750 \mathrm{mg} \text {, Vit. B12 } 9.600 \\
\mathrm{mcg} \text {, Vit. B2 } 4.800 \mathrm{mg} \text {, Vit. B6 2.500 mg, Vit. D3 } \\
1.600 .000 U \mathrm{U}, \text { Vit. E } 14.000 \mathrm{mg} \text {, Vit. K3 } 1.440 \mathrm{mg} \text {. } \\
\text { Suplemento mineral - contém em } 0,5 \mathrm{~kg}= \\
\text { Manganês } 150.000 \mathrm{mg} \text {, Zinco } 100.000 \mathrm{mg} \text {, } \\
\text { Ferro } 100.000 \mathrm{mg} \text {, Cobre } 16.000 \mathrm{mg} \text {, lodo } 1.500 \\
\text { mg. }\end{array}$} \\
\hline
\end{tabular}

Os dados coletados foram submetidos à análise de variância e as médias estimadas avaliadas pelo teste de Tukey à $5 \%$ de significância utilizando o programa computacional SAS (2008).

\section{RESULTADOS}

Os resultados da relação pinto/ovo encontram-se na Tabela 2 . Foram observadas diferenças significativas $(p<0,05)$ para peso do ovo e peso do pinto entre turnos de coleta, onde 0 turno de coleta noturno apresentou pesos significativamente melhores, corroborando com os resultados encontrados por Novo et al. (1997). A perda de peso do ovo também apresentou diferenças significativas $(p<0,05)$ entre dias de transferência, sendo menor quando os ovos foram transferidos aos 16 dias.

Tabela 2. Relação pinto/ovo de ovos coletados em diferentes turnos de coleta e transferidos em diferentes períodos.

\begin{tabular}{|c|c|c|c|c|}
\hline \multirow[b]{2}{*}{ Fatores } & \multicolumn{4}{|c|}{ Variáveis } \\
\hline & $\begin{array}{l}\text { Peso do } \\
\text { Ovo (g) }\end{array}$ & $\begin{array}{l}\text { Perda de } \\
\text { Peso (\%) }\end{array}$ & $\begin{array}{l}\text { Peso do } \\
\text { Pinto }(\mathrm{g})\end{array}$ & $\begin{array}{l}\text { Correlação } \\
\text { Pinto/Ovo }\end{array}$ \\
\hline \multicolumn{5}{|l|}{ Turno de Coleta } \\
\hline Matutino & $56,60^{\text {w }}$ & 14,14 & $37,14^{b}$ & 64,8 \\
\hline Vespertino & $54,76^{\mathrm{b}}$ & 14,52 & $35,32^{\circ}$ & 64,6 \\
\hline Noturno & $57,96^{\mathrm{a}}$ & 13,84 & $38,70^{\mathrm{a}}$ & 66,6 \\
\hline \multicolumn{5}{|l|}{ Transferência } \\
\hline 16 Dias & 56,52 & $12,84^{\mathrm{a}}$ & 37,27 & 66,0 \\
\hline 19 Dias & 56,35 & $15,50^{\mathrm{b}}$ & 36,88 & 65,3 \\
\hline Efeito & \multicolumn{4}{|c|}{ P Valor } \\
\hline Turno de Coleta & $0,01^{*}$ & $0,78^{\text {ns }}$ & $0,01^{*}$ & $0,47^{\text {ns }}$ \\
\hline Transferência & $0,83^{\text {ns }}$ & $0,01^{*}$ & $0,40^{\text {ns }}$ & $0,61^{\text {ns }}$ \\
\hline Interação & $0,32^{\text {ns }}$ & $0,25^{\text {ns }}$ & $0,43^{\text {ns }}$ & $0,62^{\text {ns }}$ \\
\hline CV (\%) & 3,98 & 15,16 & 3,32 & 5,52 \\
\hline
\end{tabular}

CV - Coeficiente de variação; * Médias seguidas por letras minúsculas na coluna diferem entre si pelo teste de Tukey a $5 \%(p<0,05) ;$ ns - não significativo.

Os resultados para rendimentos de incubação encontram-se na Tabela 3. A eclodibilidade e a eclosão apresentaram diferenças significativas $(p<0,05)$ entre turnos de coleta e períodos de transferências, com melhores índices 

processos de incubação artificial

para ovos coletados nos períodos matutino e vespertino, e transferidos com 16 dias, discordando dos resultados obtidos por Zakaria et al (2009).

A taxa de refugos apresentou ainda diferenças significativas $(p<0,05)$ entre períodos de transferências, sendo significativamente maior em ovos transferidos aos 19 dias.

Tabela 3. Rendimentos de incubação de ovos coletados em diferentes turnos de coleta e transferidos em diferentes períodos.

\begin{tabular}{|c|c|c|c|c|}
\hline \multirow{2}{*}{ Fatores } & \multicolumn{4}{|c|}{ Variáveis } \\
\hline & $\begin{array}{c}\text { Fertilidade } \\
(\%)\end{array}$ & $\begin{array}{c}\text { Eclodibilidade } \\
(\%)\end{array}$ & $\begin{array}{c}\text { Eclosão } \\
(\%)\end{array}$ & $\begin{array}{c}\text { Refugos } \\
(\%)\end{array}$ \\
\hline \multicolumn{5}{|l|}{ Turno de Coleta } \\
\hline Matutino & 92,86 & $87,86^{\mathrm{ab}}$ & $81,43^{\mathrm{ab}}$ & 2,86 \\
\hline Vespertino & 91,43 & $94,86^{\mathrm{a}}$ & $85,71^{a}$ & 2,86 \\
\hline Noturno & 92,86 & $82,76^{b}$ & $77,14^{b}$ & 2,86 \\
\hline \multicolumn{5}{|l|}{ Transferência } \\
\hline 16 Dias & 94,28 & $92,22^{\mathrm{a}}$ & $86,66^{\mathrm{a}}$ & $1,90^{\mathrm{a}}$ \\
\hline 19 Dias & 90,47 & $84,76^{b}$ & $76,19^{b}$ & $3,81^{\mathrm{b}}$ \\
\hline Efeito & \multicolumn{4}{|c|}{ P Valor } \\
\hline Turno de Coleta & $0,93^{\text {ns }}$ & $0,01^{*}$ & $0,03^{*}$ & $0,89^{\text {ns }}$ \\
\hline Transferência & $0,30^{\text {ns }}$ & $0,02^{*}$ & $0,04^{*}$ & $0,03^{*}$ \\
\hline Interação & $0,42^{\mathrm{ns}}$ & $0,12^{\text {ns }}$ & $0,18^{\mathrm{ns}}$ & $0,26^{\mathrm{ns}}$ \\
\hline CV (\%) & 13,89 & 16,07 & 17,02 & 21,83 \\
\hline
\end{tabular}

CV - Coeficiente de variação; * Médias seguidas por letras minúsculas na coluna diferem entre si pelo teste de Tukey a $5 \%(p<0,05) ;$ ns - não significativo.

Os resultados para mortalidade embrionária encontram-se na Tabela 4. Foram observadas diferenças significativas $(p<0,05)$ para mortalidade tardia entre turnos de coleta e períodos de transferência dos ovos, com ovos coletados no período noturno e ovos transferidos com 19 dias apresentando piores resultados.

Notadamente, conforme afirma Novo et al. (1997) e Brian (2000), pelo fato dos ovos permanecerem mais tempo na incubadora, pode haver uma maior mortalidade tardia dos ovos pela necessidade de alteração das condições ambientes que a fisiologia do embrião exige por volta dos 17 dias em média. Quando não há estas modificações, o embrião ainda persiste em permanecer vivo, todavia, em condições que podem desfavorecer seu desenvolvimento ideal, e ocasionar sua morte.

Tabela 4. Mortalidade embrionária (Precoce, Intermediária e Tardia) em ovos coletados em diferentes turnos de coleta e transferidos em diferentes períodos.

\begin{tabular}{lccc}
\hline \multirow{2}{*}{ Fatores } & \multicolumn{3}{c}{ Variáveis } \\
\cline { 2 - 4 } & Precoce (\%) & Intermediária (\%) & Tardia (\%) \\
\hline Turno de Coleta & & 2,85 & $4,28^{\text {ab }}$ \\
\hline Matutino & 8,57 & 2,85 & $0,00^{\text {a }}$ \\
Vespertino & 8,57 & 2,85 & $9,99^{\text {b }}$ \\
Noturno & 7,14 & 2,85 & $1,90^{\text {a }}$ \\
\hline Transferência & & 2,85 & $7,62^{\text {b }}$ \\
\hline 16 Dias & 6,67 & P Valor \\
19 Dias & 9,52 & $0,89^{\text {ns }}$ & $0,01^{\text {* }}$ \\
\hline Efeito & & $0,12^{\text {ns }}$ & $0,01^{\text {* }}$ \\
\hline Turno de Coleta & $0,25^{\text {ns }}$ & $0,19^{\text {ns }}$ \\
Transferência & $0,85^{\text {ns }}$ & 12,47 & 17,11 \\
Interação & $0,21^{\text {ns }}$ & $0,15^{\text {ns }}$ \\
\hline CV (\%) & 19,95 &
\end{tabular}

CV - Coeficiente de variação; * Médias seguidas por letras minúsculas na coluna diferem entre si pelo teste de Tukey a $5 \%(p<0,05) ;$ ns - não significativo.

Os resultados para análise térmica estão dispostos na Tabela 5. Foram observadas diferenças significativas $(p<0,05)$ entre dias de transferência, onde pintos oriundos de ovos transferidos aos 19 dias apresentaram maior temperatura corporal total, todavia, menor temperatura retal, o que pode de certa forma, constatar possíveis alterações fisiológicas relacionadas a estresse térmico durante o manejo de incubação.

Tabela 5. Análise térmica de pintos oriundos de ovos coletados em diferentes turnos de coleta e transferidos em diferentes períodos.

\begin{tabular}{lcc}
\hline \multirow{2}{*}{ Fatores } & \multicolumn{2}{c}{ Variáveis } \\
\cline { 2 - 3 } & $\begin{array}{c}\text { Temperatura Média Superficial } \\
\left({ }^{\circ} \mathrm{C}\right)\end{array}$ & $\begin{array}{c}\text { Temperatura da Cloaca } \\
\left({ }^{\circ} \mathrm{C}\right)\end{array}$ \\
\hline Turno de Coleta & & 31,56 \\
\hline Matutino & 31,88 & 31,80 \\
Vespertino & 31,55 & 32,06 \\
Noturno & 32,30 & \\
\hline Transferência & & $32,85^{\mathrm{a}}$ \\
\hline 16 Dias & $31,56^{\mathrm{b}}$ & $30,77^{\mathrm{b}}$ \\
19 Dias & $32,27^{\mathrm{a}}$ & \\
\hline Efeito & & $\mathrm{P}$ Valor \\
\hline Turno de Coleta & $0,19^{\text {ns }}$ & $0,50^{\text {ns }}$ \\
Transferência & $0,04^{*}$ & $0,01^{*}$ \\
Interação & $0,17^{\text {ns }}$ & $0,42^{\text {ns }}$ \\
\hline CV (\%) & 2,84 & 2,97 \\
\hline
\end{tabular}


CV - Coeficiente de variação; * Médias seguidas por letras minúsculas na coluna diferem entre si pelo teste de Tukey a $5 \%(p<0,05)$; ns - não significativo.

Os resultados da análise do trato gastrointestinal e órgãos anexos estão expostos na Tabela 6 . Não foram observadas diferenças significativas $(p<0,05)$ entre turnos de coleta, dias de transferência e na interação entre os fatores sobre os parâmetros avaliados.

Tabela 6. Análise do trato gastrointestinal e órgãos anexos de pintos oriundos de ovos coletados em diferentes turnos de coleta e transferidos em diferentes períodos.

\begin{tabular}{|c|c|c|c|c|c|}
\hline \multirow[b]{2}{*}{ Fatores } & \multicolumn{5}{|c|}{ Variáveis } \\
\hline & $\begin{array}{c}\text { Peso } \\
\text { do } \\
\text { Coração } \\
\text { (g) }\end{array}$ & $\begin{array}{c}\text { Peso } \\
\text { do } \\
\text { Fígado } \\
\text { (g) }\end{array}$ & $\begin{array}{c}\text { Peso } \\
\text { dos } \\
\text { estômagos } \\
(\mathrm{g})\end{array}$ & $\begin{array}{l}\text { Peso do } \\
\text { Saco } \\
\text { Vitelino } \\
\text { (g) }\end{array}$ & $\begin{array}{l}\text { Comprimento } \\
\text { do Sistema } \\
\text { Digestivo } \\
\text { (cm) }\end{array}$ \\
\hline \multicolumn{6}{|l|}{ Turno de Coleta } \\
\hline Matutino & 0,32 & 1,04 & 2,63 & 3,51 & 43,89 \\
\hline Vespertino & 0,30 & 1,03 & 2,33 & 4,18 & 43,14 \\
\hline Noturno & 0,30 & 1,12 & 2,46 & 4,99 & 42,78 \\
\hline \multicolumn{6}{|l|}{ Transferência } \\
\hline 16 Dias & 0,31 & 1,07 & 2,47 & 4,26 & 42,67 \\
\hline 19 Dias & 0,30 & 1,05 & 2,48 & 4,19 & 43,87 \\
\hline Efeito & \multicolumn{5}{|c|}{ P Valor } \\
\hline Turno de Coleta & $0,73^{\text {ns }}$ & $0,50^{\text {ns }}$ & $0,07^{\text {ns }}$ & $0,08^{\text {ns }}$ & $0,54^{\text {ns }}$ \\
\hline Transferência & $0,55^{\mathrm{ns}}$ & $0,75^{\text {ns }}$ & $0,90^{\mathrm{ns}}$ & $0,89^{\text {ns }}$ & $0,15^{\mathrm{ns}}$ \\
\hline Interação & $0,62^{\text {ns }}$ & $0,63^{\text {ns }}$ & $0,21^{\text {ns }}$ & $0,54^{\text {ns }}$ & $0,32^{\text {ns }}$ \\
\hline CV (\%) & 18,78 & 16,63 & 11,48 & 23,59 & 5,23 \\
\hline
\end{tabular}

CV - Coeficiente de variação; * Médias seguidas por letras minúsculas na coluna diferem entre si pelo teste de Tukey a $5 \%(p<0,05) ;$ ns - não significativo.

Os resultados de desempenho encontram-se dispostos na Tabela 7 . Não foram observadas diferenças significativas $(p<0,05)$ entre turnos de coleta, dias de transferência e na interação entre fatores.

Estes resultados podem estar diretamente relacionados com os resultados do trato gastrointestinal $\mathrm{e}$ órgãos anexos. Todavia, por terem sido avaliados em um curto prazo, podem não demonstrar efetivamente os efeitos dos processos de incubação sobre o desenvolvimento dos pintos.

\section{DISCUSSÃO}

Nos rendimentos de incubação, verificou-se uma crescente taxa de perda de peso dos ovos à medida que houve avanço no desenvolvimento embrionário, demonstrando assim que com o decorrer da incubação, o conteúdo de água do ovo vai sendo perdido cada vez mais para o meio externo, independe de fatores da matriz, todavia, interligados com o manejo durante os processos de incubação artificial dos ovos conforme é descrito por Tazawa e Whittow (2000)

Tabela 7. Desempenho após sete dias de pintos oriundos de ovos coletados em diferentes turnos de coleta e transferidos em diferentes períodos.

\begin{tabular}{lccc}
\hline \multicolumn{1}{c}{ Fatores } & \multicolumn{3}{c}{ Variáveis } \\
\cline { 2 - 4 } & $\begin{array}{c}\text { Consumo de } \\
\text { ração } \\
\text { (g/ave) }\end{array}$ & $\begin{array}{c}\text { Ganho de } \\
\text { Peso } \\
(\mathrm{g} / \text { ave })\end{array}$ & $\begin{array}{c}\text { Conversão } \\
\text { Alimentar } \\
(\mathrm{g} / \mathrm{g})\end{array}$ \\
\hline Turno de Coleta & & 18,90 & \\
\hline Matutino & 72,37 & 16,57 & 4,01 \\
Vespertino & 71,20 & 20,85 & 4,47 \\
Noturno & 66,90 & 18,93 & 3,21 \\
\hline Transferência & & 18,62 & 3,80 \\
\hline 16 Dias & 70,15 & P Valor & 3,97 \\
19 Dias & 70,17 & $0,33^{\text {ns }}$ & $0,17^{\text {ns }}$ \\
\hline Efeito & & $0,88^{\text {ns }}$ & $0,72^{\text {ns }}$ \\
\hline Turno de Coleta & $0,41^{\text {ns }}$ & $0,35^{\text {ns }}$ & $0,21^{\text {ns }}$ \\
\hline Transferência & $0,96^{\text {ns }}$ & 20,38 & 21,59 \\
Interação & $0,38^{\text {ns }}$ & 8,32 &
\end{tabular}

CV - Coeficiente de variação; * Médias seguidas por letras minúsculas na coluna diferem entre si pelo teste de Tukey a $5 \%(p<0,05)$; ns - não significativo.

Tona et al. (2001) afirmam ainda que ao prologar-se o período de transferência dos ovos, aumenta-se a incidência de mortalidade embrionária e/ou má formação de pintos durante o processo de desenvolvimento embrionário, o que relaciona tanto os de rendimentos de incubação quanto a mortalidade embrionária inserida neste contexto, atribuindo uma relação de manejo-consequência, onde a medida que altera-se os protocolos de atuação na máquina de incubação ou no manejo dos ovos, há uma resposta fisiológica direta do embrião.

É conhecido que a duração do período de coleta e armazenamento dos ovos apresenta correlação inversa com a eclodibilidade, e, em termos de fase 

processos de incubação artificial

da mortalidade embrionária, quanto maior 0 período de armazenamento, maior a mortalidade (BOLELI, 2003) e maior volume de pintos de má qualidade, devido a perda inadequada de umidade, má cicatrização dos umbigos, penugem com aspecto pegajoso e maior janela de nascimento (MACHADO et al., 2010).

Fasenko et al. (2001) afirmaram que os efeitos da coleta e estocagem na eclodibilidade dos ovos dependem do período, tempo de estocagem e do estágio de desenvolvimento em que o embrião se encontra no momento da postura. Embriões em estágios mais avançados de desenvolvimento são mais resistentes a uma estocagem mais prolongada que embriões menos desenvolvidos. Segundo Reijrink et al. (2009) quando termina a estocagem, os embriões completaram a formação do hipoblasto, e a migração celular e sua diferenciação é mínima.

Quanto a termorregulação dos pintos com um dia, os resultados demonstraram-se dentro de uma faixa de aceitabilidade, conforme afirmam Furlan e Macari (2008). Estes autores relatam ainda que a zona de conforto térmico de pintos encontra-se em uma temperatura ambiente entre 33 e $35^{\circ} \mathrm{C}$ e umidade relativa entre 65 a $70 \%$. E a partir do desenvolvimento do frango de corte e a consequente maturação do sistema termorregulador, que atinge sua plenitude entre 10 e 15 dias de vida pósnatal, esta zona de conforto térmico é reduzida de $33{ }^{\circ} \mathrm{C}$ para $24{ }^{\circ} \mathrm{C}$, com quatro semanas de idade e, para $21^{\circ} \mathrm{C}$ a $22{ }^{\circ} \mathrm{C}$ com seis semanas de idade.

Fora desta zona de conforto térmico, os animais tendem a responder com alterações comportamentais, bioquímicas e fisiológicas (NAZARENO et al., 2009), refletindo em decréscimo produtivo, reprodutivo e da resistência do organismo, sendo que extremos podem vir a ser letais.

Esta condição ambiental deve ser manejada, na medida do possível, desde a máquina de incubação até o manejo de galpões visando à permanência dos animais na sua faixa de conforto térmico, pois nessas condições, os sistemas de regulação de temperatura atuam com um dispêndio menor de energia, o que implica em um desenvolvimento mais eficiente, dentre outros benefícios (LIMA et al., 2009).

Quanto ao desenvolvimento anatômico dos pintos e análise de desempenho, autores como Tona et al. (2001), Zakaria et al. (2009) e Rufino et al. (2014) afirmam que mesmo não apresentando efeito significativo, os processos de incubação artificial podem influenciar diretamente no desenvolvimento destes posteriormente, indicando que modificações nos procedimentos de manipulação e incubação dos ovos podem afetar o desenvolvimento dos embriões e pintos.

\section{CONCLUSÕES}

Os turnos de coleta e períodos de transferência dos ovos podem influenciar diretamente processos de incubação de ovos de matrizes semipesadas. Os turnos de coleta matutino e vespertino apresentaram melhores resultados de rendimentos de incubação e mortalidade embrionária, com ovos e pintos menores. Ovos transferidos com 16 dias apresentaram melhores resultados de perda de peso do ovo, peso do pinto e rendimentos de incubação.

\section{REFERÊNCIAS}

BARBOSA, V.M.; BAIÃO, N.C. Formação e estrutura do ovo incubável. In: BARBOSA, V.M. (Ed) Fisiologia da incubação e desenvolvimento 
embrionário. Belo Horizonte: FEPMVZ, p. 01-09, 2011.

BOLELI, I.C. Estresse, mortalidade e malformações embrionárias. In: MACARI, M.; GONZALES, E. Manejo da incubação. Campinas: FACTA, 2003. Cap. 4.4, p. 394-434.

BRIAN, H. Incubation, the physical requeriments. International Hatchery Pratice, v. 14, p. 25, 2000.

CHOI, J.H.; MILES, R.D.; ARAFA, A.S. et al. The influence of oviposition time on egg weight, shell quality and blood phosphorus. Poultry Science, v. 60, p. 824-828, 1981.

GIGLI, A.C.S.; BARACHO, M.S.; NÄÄS, I.A. et al. Environmental Conditions in Broiler Multi-Stage Setter - A Case Study. Science Agricultural, v. 66. n. 2, p. 145-149, 2009.

FAZENKO, G.M.; ROBINSON, F.E.; WHELAN, A. I. Prestorage Incubation of Long-Term Stored Broiler Breeder Eggs: 1. Effects on Hatchability. Poultry Science, v. 80, p. 1406-1411, 2001.

FURLAN, R.L.; MACARI, M. Termorregulação. In: Macari, M.; Furlan R.L.; Gonzales, E. Fisiologia aviária aplicada a frangos de corte. 2 ed. Jaboticabal: Funesp, p. 209-230, 2008.

LIMA, K.R.S.; ALVES, J.A.K.; ARAÚJO, C.V.; MANNO, M.C.; JESUS, M.L.C.; FERNANDES, D.L.; TAVARES, F. Avaliação do ambiente térmico interno em galpões de frango de corte com diferentes materiais de cobertura na mesorregião metropolitana de Belém. Revista de Ciências Agrárias, n. 51, p. 37-50, 2009.

MACHADO, A.R.; SILA, M.S.; FONSECA, B.B. Viragem de Ovos de Avós Pesadas (Gallus gallus) Durante a Estocagem. Revista Avisite, 2010.
NAZARENO, A.C.; PANDORFI, H.; ALMEIDA, G.L.P.; GIONGO, P.R.; PEDROSA, E.M.R.; GUISELINI, C. Avaliação do conforto térmico e desempenho de frangos de corte sob regime de criação diferenciado. Revista Brasileira de Engenharia Agrícola e Ambiental, v. 13, n. 6 , p. 802-808, 2009.

NORTH, M.O. Commercial Chicken Production Manual. (3 Ed). Oceanside: THE AVI PUBLISHING COMPANY, 1984. 710p.

NOVO, R.P.; GAMA, L.T.; SOARES, M.C. Effects of oviposition time, hen age, and extra dietary calcium on egg characteristics and hatchability. Journal Applied Poultry Research, v. 6, p. 335343, 1997.

REIJRINK, I.A.M.; MEIJERHOF, R.; KEMP, B. Influence of Prestorage Incubation on Embryonic Development, Hatchability, and Chick Quality. Poultry Science, v. 88, p. 2649-2660, 2009.

RUFINO, J.P.F.; CRUZ, F.G.G.; MACHADO, N.J.B.; BRASIL, R.J.M.; PEREIRA, P.A.M.; FARIAS, E.G. Processos de incubação artificial associados à aplicação de diferentes métodos reprodutivos em matrizes semipesadas. Revista Brasileira de Saúde e Produção Animal, v. 15, p. 765-773, 2014.

SAS. Statistical Analysis System. SAS/STAT Software Version 9.2. Cary: SAS Institute Inc., 2008.

TAZAWA, H.; WHITTOW, G.C. Incubation physiology. In: WHITTOW, G.C. Sturkie's Avian Physiology, cap. 24, p. 617-634, 2000.

TONA, K.; DECUYPERE, E.; COUCKE, W. Effects of strain, hen age and 
transferring eggs from turning to stationary trays after 15 to 18 days of incubation. British Poultry Science, v. 42, p. 663-667, 2001.

TONA, K.; ONAGBESAN, O.; DE KETELAERE, B.; DECUYPERE, E. et al. Effects of turning duration during incubation on corticosterone and thyroid hormone levels, gas pressure in air cell, chick quality, and juvenile growth. Poultry Science, v. 82, p. 1947-1979, 2003.

ZAKARIA, A.H.; PLUMSTEAD, P.W.; ROMERO-SANCHEZ, $H$. et al. The effects of oviposition time on egg weight loss during storage and incubation, fertility and hatchability of broiler hatching eggs. Poultry Science, v. 88, p. 2712-2717, 2009. 